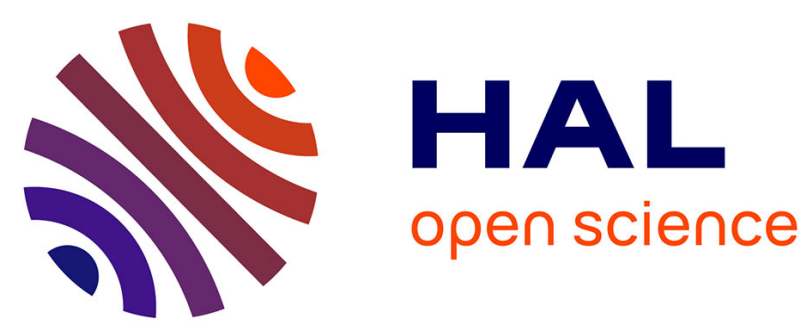

\title{
ON THE USE OF INTEGRATING SPHERE REFLECTOMETERS FOR MEASURING THE SOLAR ABSORPTANCE OF SELECTIVE SURFACES
}

T. Ricolfi, M. Battuello

\section{- To cite this version:}

T. Ricolfi, M. Battuello. ON THE USE OF INTEGRATING SPHERE REFLECTOMETERS FOR MEASURING THE SOLAR ABSORPTANCE OF SELECTIVE SURFACES. Journal de Physique Colloques, 1981, 42 (C1), pp.C1-373-C1-381. 10.1051/jphyscol:1981127 . jpa-00220677

HAL Id: jpa-00220677 https://hal.science/jpa-00220677

Submitted on 1 Jan 1981

HAL is a multi-disciplinary open access archive for the deposit and dissemination of scientific research documents, whether they are published or not. The documents may come from teaching and research institutions in France or abroad, or from public or private research centers.
L'archive ouverte pluridisciplinaire HAL, est destinée au dépôt et à la diffusion de documents scientifiques de niveau recherche, publiés ou non, émanant des établissements d'enseignement et de recherche français ou étrangers, des laboratoires publics ou privés. 
JOURNAL DE PHYSIQUE

Colloque 1 , supplément au $n^{\circ} 1$, Tome 42 , janvier 1981

page $\mathrm{C} 1-373$

ON THE USE OF INTEGRATING SPHERE REFLECTOMETERS FOR MEASURING THE SOLAR ABSORPTANCE OF SELECTIVE SURFACES

T. Ricolfi and M. Battue11o

CNR - Istituto di Metrologia "G.Colonnetti" Torino, Italy

Résumë.- Les absorptivités solaires sont souvent dérivées des valeurs de réflectivité mesurées au moyen de dispositifs employant des sphères intégrantes. Les instruments de ce genre ont deux manières de fonctionnement, selon qu'on mesure les réflectivités spectrales ou intégrées. Bien que les absorptivités solaires dérivées des données spectrales soient intrinsèquement plus précises, on trouve en commerce des réflectomètres conçus de façon à mesurer les réflectivités intégrées plutôt que spectrales. Ces instruments sont souvent pourvus de sources de radiation qui ne s'accordent pas avec le spectre solaire, et/ou de détecteurs montrant une réponse caractérisée par la sélectivité spectrale : en ligne de principe ils peuvent par conséquent être sujets d'erreurs lorsqu'ils sont destinés aux surfaces sélectives. Dans le but de fournir une évaluation de l'erreur, on a analysé la théorie de la mesure par rapport à quelques échantillons sélectifs bien caractêrisés par leurs propriétés réflectives. La validité des résultats a été confirmée expérimentalement avec l'emploi d'une sphère intégrante equipée de sources et dêtecteurs différents.

Abstract. - Solar absorptances are often derived from the reflectance values measured with devices which make use of integrating spheres. Instruments of this type can be operated in two different ways, according to whether spectral or integrated reflectances are measured. Though solar absorptances derived from spectral data are inherently more accurate, some commercially available reflectometers are found which are conceived for measuring integrated rather than spectral reflectances. Since these instruments are often provided with radiation sources which do not match the solar spectrum and/or detectors showing a spectrally selective response, they could in principle be affected by errors when dealing with selective surfaces. With the aim of giving an error estimate, the theory of the measurement was analyzed with, reference to some selective samples well characterized for their reflectance properties. The results were then given an experimental. validation by using an integrating sphere equipped with different sources and detectors.

1. Introduction.- The most popular technique for measuring solar absorptance is that of the integrating sphere reflectometer used in the comparison mode. This allows the reflectance of a sample under test to be derived in terms of the known reflectance of a reference sample. Solar absorptance is then obtained according to Kirchhoff's law. Instruments of this type can be operated in two different ways, according to whether spectral or integrated reflectance values are measured. While in thefirst case a relatively large number of measurements are taken to 
provide data for numerical integration over the solar spectrum, in the second case the same integrated reflectance is directly obtained with a single measurement. Thus, a noticeable reduction of the measuring time is achieved, which may be particularly appreciated when dealing with a large number of samples. In addition, also the cost of the apparatus is drastically reduced, being no need for high sensitivity detectors and light dispersing devices, such as monochromators. For these reasons, some commercially available reflectometers are conceived for measuring integrated reflectances directly. Though these instruments are sufficiently accurate for many purposes, nevertheless they could in principle be affected by non negligible errors when investigating selective surfaces, that is materials having a wavelength dependent reflectance. In fact, they are often provided with radiation sources which do not match the solar spectrum and/or detectors which show a selective response. Furthermore, errors may be due also to a slight selectivity of the sphere coating itself, as suggested by Dunkle et al./1/, who first measured directly integrated reflectances.

With the aim of finding how the combined action of source, detector and sphere coating can influence the results, the general theory of the measurement was first established and applied to some particular situations. An experimental validation was then achieved by means of an integrating sphere equipped with interchangeable sources and detectors. 2. Theory.- A schematic view of an integrating sphere reflectometer of the comparison type is shown in figure 1 .

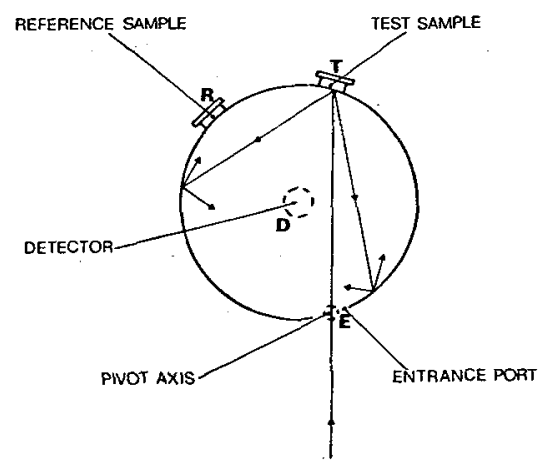

Fig.1.- Schematic of an integrating sphere reflectometer of the comparison type.

A radiation beam from an external source is alternatively focused on the sample under test $T$ and on the reference sample $R$. If $S_{T}$ and $S_{R}$ are the detector outputs, the following relation holds :

$$
\rho_{\mathrm{T}}=\frac{\mathrm{S}_{\mathrm{T}}}{\mathrm{S}_{\mathrm{R}}} \rho_{\mathrm{R}}
$$


in which $\rho_{T}$ and $\rho_{R}$ are the reflectances of the samples, being the latter a known quantity.

The measured reflectance $\rho_{\mathrm{T}}$ is spectrally characterized by the nature of the incoming radiation. When this is a monochromatic light beam, the spectral reflectance $\rho_{\mathrm{T}}(\lambda)$ is measured. The solar absorptance $\alpha_{\mathrm{T}}(\mathrm{S})$ is ther derived from the equation :

$$
\alpha_{T}(s)=1-\rho_{T}(S)=1-\frac{\int_{0}^{\infty} I_{S}(\lambda) \rho_{T}(\lambda) d \lambda}{\int_{0}^{\infty} I_{S}(\lambda) d \lambda}
$$

where $\rho_{T}(S)$ is the sample reflectance weighted on the spectral distribution $I_{S}(\lambda)$ of the solar radiation. When, instead, a radiation beam matching the solar spectral distribution is used, the solar absorptance is readily obtained as :

$$
\alpha_{T}(S)=1-\rho_{T}(S)=1-\frac{S_{T}}{S_{R}} \rho_{R}(S)
$$

By comparing equations (2) and (3) it is evident that, from an operative point of view, there is much to gain in using the latter, since it requires only one reflectance measurement.

In practice, things are not so straightforward because the ratio of output signals is dependent on such quantities as the spectral distribution of the radiation beam, the spectral sensitivity of the detector, the spectral reflectance of the sphere coating, other than, of course, of the two samples.

In fact, this ratio may be mathematically expressed as follows :

$$
\frac{S_{T}}{S_{R}}=\frac{\int_{0}^{\infty} I(\lambda) F_{T}(\lambda) \sigma(\lambda) d \lambda}{\int_{0}^{\infty} I(\lambda) F_{R}(\lambda) \sigma(\lambda) d \lambda}
$$

where $: I(\lambda)$ is the spectral distribution of the radiation beam which, in an ideal case, equals $I_{S}(\lambda)$;

$\sigma(\lambda)$ is the spectral sensitivity of the detector ;

$F_{T}(\lambda)$ and $F_{R}(\lambda)$ are the so called "sphere efficiencies", which physically represent the fraction of the entering beam which is collected at the detector port after reflection at $T$ and $R$, respectively.

The generalized theory of the integrating sphere /2/ applied to the present case provides the following expression for $F_{T}(\lambda)$ and $F_{R}(\lambda)$ :

$$
F_{T, R}(\lambda)=\frac{\frac{a_{T, R}}{A} \rho_{T, R}(\lambda)}{1-\rho_{W}(\lambda)\left(1-\frac{a_{E}+a_{D^{+}} a_{T}+a_{R}}{A}\right)-\frac{a_{T}}{A} \rho_{T}(\lambda)-\frac{a_{R}}{A} \rho_{R}(\lambda)}
$$


in which : $a_{E}, a_{D^{\prime}} a_{T}$ and $a_{R}$ are the areas of the four ports (see Fig.I); $A$ is the area of the sphere;

$\rho_{W}(\lambda)$ is the spectral reflectance of the sphere wall.

Equations (3), (4) and (5) may be used, starting from known values of $\rho_{T}(\lambda)$, to foresee the measured values of $\rho_{T}(S)$ when a sphere is combined with sources and detectors whose characteristics are known. The results, compared with those obtained from equation (2), which is nothing more but a definition, will then disclose the errors which may arise when measuring $\rho_{\mathrm{T}}(\mathrm{S})$ directly.

3. Experiment and calculations. - An experimental validation of the above analysis was achieved by accurately testing for their reflectance properties four samples provided from different sources. A description of the samples is given in table $I$, where the thermal emittances, which had been previously measured with a heated cavity reflectometer, are also reported.

\begin{tabular}{|c|l|l|c|}
\hline sample & \multicolumn{1}{|c|}{ Nature } & \multicolumn{1}{|c|}{ Source } & Enittance \\
\hline No.1 & Black chrome on brass & Our laboratory & 0.04 \\
No.2 & Black chrome on aluminum & Commercial & 0.18 \\
No.3 & Unknown coating on aluminum $\quad\left(^{\circ}\right)$ & Commercial & 0.11 \\
No.4 & Copper oxide on copper & Commercial & 0.11 \\
\hline
\end{tabular}

Table I.- Description of the tested samples.

$\left({ }^{\circ}\right)$ The nature of the black coating was not disclosed by the supplier

\begin{tabular}{|c|c|c|c|c|c|}
\hline Sample & \multicolumn{3}{|c|}{ Solar absorptance } \\
\hline & $\begin{array}{c}\text { Fram spectral } \\
\text { data (AM2) }\end{array}$ & $\begin{array}{c}\text { Xe arc } \\
+ \\
\text { Si }\end{array}$ & $\begin{array}{c}\text { Xe arc } \\
+ \\
\text { Pyroelectric }\end{array}$ & $\begin{array}{c}\text { Halogen } \\
+ \\
\text { Si }\end{array}$ & $\begin{array}{c}\text { Halogen } \\
+ \\
\text { No.1 }\end{array}$ \\
\cline { 2 - 6 } No.2 & 0.917 & 0.943 & 0.931 & 0.947 & 0.917 \\
No.3 & 0.913 & 0.936 & 0.916 & 0.928 & 0.884 \\
No.4 & 0.900 & 0.948 & 0.916 & 0.957 & 0.912 \\
& 0.865 & 0.868 & 0.869 & 0.867 & 0.862 \\
\hline
\end{tabular}

Table II.- Calculated solar absorptances of the tested samples.

The emittance values, as compared with the solar absorptances reported in table II, show that a common feature to the samples was their fairly good selectivity.

The reflectance measurements were performed with a sphere $300 \mathrm{~mm}$ in diameter, internally coated with a $\mathrm{BaSO}_{4}$ paint (Eastman 6080 white reflec- 
tance coating), while pressed $\mathrm{BaSO}_{4}$ powder (Eastman 6091 white reflectance standard) was used to prepare the reference sample.

To obtain the spectral data, a grating monochromator (Perkin Elmer Mod. 210) with a tungsten strip lamp provided for the source. Three different detectors, namely : a photomultiplier (EMI 9558QB), a Si photodiode and a $\mathrm{PbS}$ photoconductor, were required to span the spectral region from 0.35 to $2 \mu \mathrm{m}$. This region is generally considered to be sufficiertly wide to give an accurate representation of the solar absorptance when averaging the spectral data on the solar distribution for air mass 2 (AM2) as given by Moon /3/.

The measured spectral reflectances have been plotted in figure 2 .

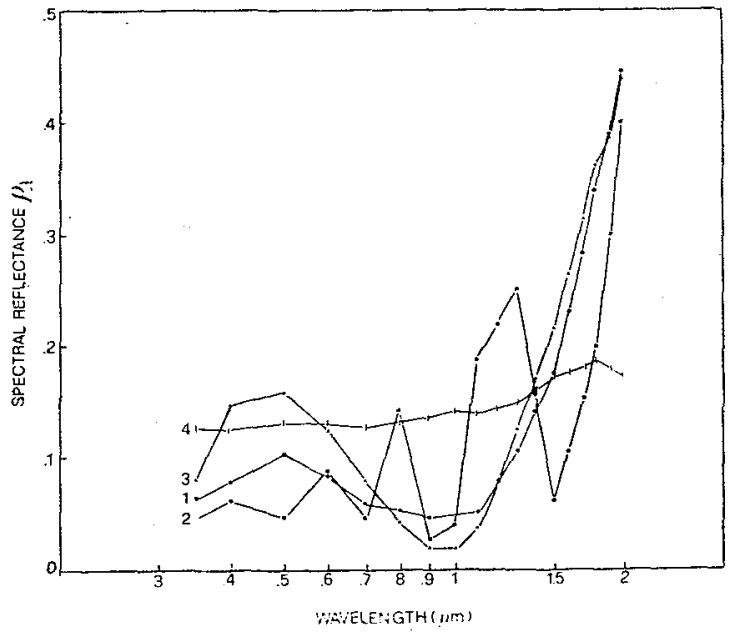

Fig.2.- Spectral reflectance curves of the samples listed in table $I$.

They were used to calculate, according to equations (3), (4) and (5), the integrated $\alpha_{T}(S)$ values that would be obtained with direct measurements. To provide meaningful imputs to these equations, we selected two types of both detectors and sources among those most widely used, thus giving rise to four possible combinations. The sources were an unfiltered Xe compact arc lamp and a tungsten-halogen lamp, whose spectral irradiances have been plotted in figure 3. The detectors were a silicon photodiode, whose spectral responsivity is shown in figure 4 , and pyroelectric sensor, which actually was a neutral detector having a constant responsivity over the spectrum.

The spectral reflectance data for the $\mathrm{BaSO}_{4}$ paint and powder were derived from the literature /4-5/.

The results of calculations are shown in table II, where the solar absorptances as obtained from spectral data through equation (2) have been reported for sake of comparison in the second column. 

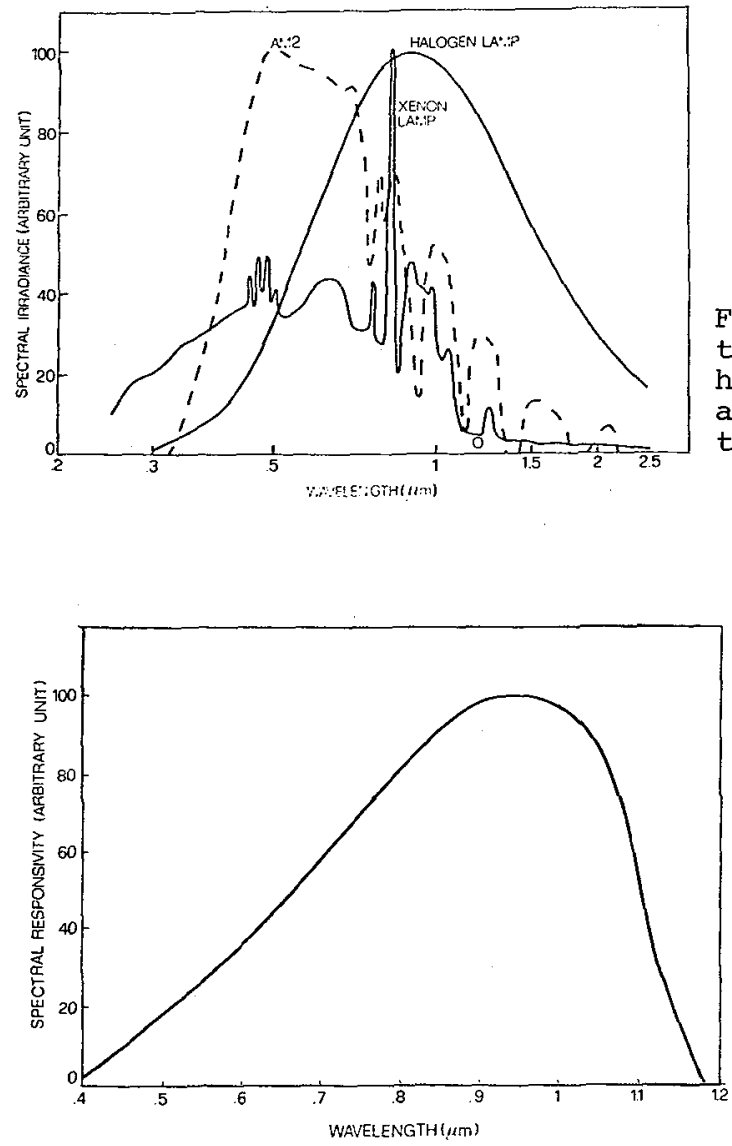

Fig.3.- Spectral irradiances of the Xe compact arc and tungstenhalogen lamps. The solar irradiance for air mass 2 has been plotted for sake of. comparison.
Fig.4.- Spectral sensitivity of the silicon photodiode.

In order to check the reliability of the data of tableII, the integrated $\alpha_{T}(S)$ were actually measured, equipping the sphere with the sources and detectors previously considered. To make these measurements, the radiation beams from the sources were focused directly onto the samples through a quartz lens, thus by-passing the monochromator. The experiment was highly successful, since none of the measured values differed from the calculated ones by more than 0.005 absorptance units. This result confirmed that both the mathematical approach and the numerical assumptions that had been made on the spectral properties of the sources, the detectors and the $\mathrm{BaSO}_{4}$ paint and powder were correct. Finally, in order to find whether the data of table II were sufficientIy representative to provide information of general interest about the errors that occur when measuring integrated absorptances, the above calculations were extended to a number of selective surfaces described in the literature. Only those surfaces were chosen for which detailed 
spectral reflectance curves were available. The data obtained for three of them (e.g.: $\mathrm{Al}_{2} \mathrm{O}_{3}$ - Mo system /6/, iron oxide film on a steel substrate /7/, Tabor treatment No.110-30 on nickel plated copper /8/), which appeared to be of some significance because of a somewhat irregular behaviour of their spectral reflectances, have been summarized in table III.

\begin{tabular}{|c|c|c|c|c|c|}
\hline sample & \multicolumn{5}{|c|}{ solar absorptance } \\
\hline & $\begin{array}{l}\text { From spectral } \\
\text { data (AM2) }\end{array}$ & $\begin{array}{c}\mathrm{Xe} \text { arc } \\
+ \\
\mathrm{Si}\end{array}$ & $\begin{array}{c}\text { Xe arc } \\
+ \\
\text { Pyroelectric }\end{array}$ & $\begin{array}{c}\text { Halogen } \\
+ \\
\mathrm{Si}^{+}\end{array}$ & $\begin{array}{c}\text { Halogen } \\
+ \\
\text { Pyroelectric }\end{array}$ \\
\hline $\begin{array}{l}\mathrm{Al}_{2} \mathrm{O}_{3}-\mathrm{MO} \\
\text { system }\end{array}$ & 0.905 & 0.952 & 0.928 & 0.955 & 0.902 \\
\hline $\begin{array}{l}\text { Iron oxide } \\
\text { on steel }\end{array}$ & 0.881 & 0.921 & 0.908 & 0.914 & 0.873 \\
\hline $\begin{array}{l}\text { Tabor } 110- \\
30 \text { on } \mathrm{Ni} \\
\text { plated } \mathrm{Cu}\end{array}$ & 0.904 & 0.971 & 0.935 & 0.967 & 0.900 \\
\hline
\end{tabular}

Table III.- Calculated solar absorptances of the literature samples.

From the data of both tables II and III the following indications may be derived :

1- Accurate integrated absorptance measurements can be made, whichever are the source and the detector, provided that the samples are weakly selective below $2 \mu \mathrm{m}$, as shown by sample No.4.

2- The largest errors occur when using the Si photodiode in connection with samples showing an irrregular spectral reflectance : this is due to both lack of sensitivity above $1.1 . \mu \mathrm{m}$ and its wavelength dependence below.

3- In most cases the $\alpha_{T}(S)$ values are overestimated. A few exceptions occur when using a neutral detector together with the halogen lamp. They originate from the shift of the irradiance curve of the lamp towards the long wavelength side, where generally the spectral absorptance is decreasing.

4-The amountof the errors is likely to be smaller than expected. As a matter of fact, data in the literature /9/ indicate errors even larger when considering the single effect of a poor match of the solar distribution. It may be argued that the total error is to some extent lowered by the algebraic composition of the partial contribution of every single effect. Even so, however, errors of the order of 0.05 absorptance unițs 
may be taken as large when comparing the performances of selective surfaces in view of their efficiency in collecting solar energy. This may be easily understood if one refers, for example, to those applications $110 /$ for which a 0.01 increase in $\alpha_{S}$ achieves the same increase in efficiency as decreasing the thermal emittance $\varepsilon_{\text {th }}$ by 0.04 . Thus, an error of 0.05 units in $\alpha_{S}$ gives rise to the same effect as an error of 0.20 units in $\varepsilon_{t h}$. Since good selective surfaces have an emittance ofthe order of 0.10 to 0.20 , the last consideration clearly suggests the necessity of an accurate measurement of $\alpha_{S}$.

4. Conclusions.- Integrating sphere reflectometers for the direct measurement of integrated solar absorptance may be used with confidence when examining materials which show a weak spectral selectivity, at least, below $2 \mathrm{jm}$. When, instead, strongly selective surfaces are to be investigated, the results thus obtained should be considered with care. This is particularly true when the instrument is equipped with a selective detector such as the silicon photodiode. In any case, when the performances of various absorbers are to be compared on the basis of their solar absorptance and thermal emittance values, the former property should be preferably derived by numerical integration of spectral reflectance data.

The present work was supported by the Finalized Energy Programme of the National Research Council (CNR). 


\section{References}

/1/ Dunkle, R.V., Edwarảs, D.K., Gier, J.T. and Bevans, J.T., Sol. Energy 4, (1960) 27-39

/2/ Goebe1, D.G., Appl. Opt. 6, (1967) 125-128

/3/ Moon, P., J. Franklin Inst. 230, (1940) 583-617

/4/ Grum, F. and Luckey, G.W., Appl. Opt. $\underline{7}$ (1968) 2289-2294

/5/ Grum, F. and Wightman, T.E., Appl. Opt. 16, (1977) 2775-2776

/6/ Schmidt, R.N. and Janssen, J.E., Symposium on Thermal Radiation of Solids, San Francisco, (1964), NASA SP $55,509-524$

/7/ Borzoni, J.T., Coatings for Solar Collectors Symposium, American Electroplater's Society, Georgia, (1976) $89-100$

/8/ Edwards, D.K, Gier, J.T., Nelson, K.E. and Roddick R.D., Sol. Energy 6 , (1962) 1-8

19/ Mic Millan, J.A. and Peterson, E.M., Sol. Energy 22 (1979) 467-469

/10/ Pettit, R.B. and Sowell, R.R., J. Vac. Sci. Tech. 13, (1976) 596-602 